\title{
Influence of Rendering Type on the Environmental Characteristics of Expanded Polystyrene-Based External Thermal Insulation Composite System
}

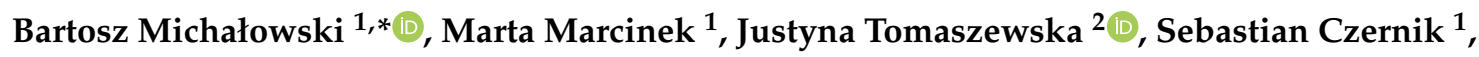 \\ Michał Piasecki $^{2}{ }^{\mathbb{D}}$, Robert Geryło ${ }^{2}$ and Jacek Michalak ${ }^{1}$ \\ 1 Research and Development Center, Atlas sp. z o. o., Kilinskiego 2, 91-421 Lodz, Poland; \\ mmarcinek@atlas.com.pl (M.M.); sczernik@atlas.com.pl (S.C.); jmichalak@atlas.com.pl (J.M.) \\ 2 Building Research Institute, Filtrowa 1, 00-611, Poland; j.tomaszewska@itb.pl (J.T.); m.piasecki@itb.pl (M.P.); \\ r.gerylo@itb.pl (R.G.) \\ * Correspondence: bmichalowski@atlas.com.pl
}

Received: 30 December 2019; Accepted: 5 March 2020; Published: 7 March 2020

\begin{abstract}
External thermal insulation systems (ETICS) are relevant facade applications of functional components allowing to reduce energy consumption in buildings to fulfill the provisions of nearly Zero-Energy Buildings (nZEBs). ETICS systems generally are made of adhesives, thermal insulation material, renders with mesh reinforcement, primers, and finish coats. Their main parameters are thermal characteristics and durability, both determined by the specific composition of the systems. Growing concerns on the environment and depletion of natural resources drive the need for the determination of the environmental characteristic of ETICS due to its growing market demand. This analysis focuses on a life cycle assessment (LCA) of a commonly used EPS based ETICS system with four different renderings, produced in several locations. The scope of this study concerns raw materials extraction, transport, production, and energy provision up to the finished, packed, and ready-for-sale product at the factory gate. The authors compared the environmental impact allocated to the $1 \mathrm{~m}^{2}$ of the produced system by taking into account the thickness of EPS and within different environmental impact categories. The results of the current impacts were compared to those obtained five years earlier, considering the technological and environmental progress of the production process.
\end{abstract}

Keywords: life cycle assessment (LCA); global warming potential (EPS); external thermal insulation system (ETICS); environmental product declaration type III (EPD)

\section{Introduction}

\subsection{Sustainable Development}

Limited natural resources and progressing degradation of the natural environment have been subjects of interest since the late sixties of the 20th century [1,2]. At that time, the idea of sustainable development had the most crucial role in shaping the way of thinking about future interrelationships between society, economy, and natural resources. The primary assumption of that concept was that at the current civilization state, progress and development can be achieved sustainably, in a way that will ensure equal access to natural resources for future generations. Nevertheless, progressive environmental degradation and excessive consumption of natural resources have forced policymakers to find a solution for further, effective development with simultaneous care of the environment, especially in the construction sector [3]. Construction under the principles of sustainable development requires that the design and construction of buildings will ensure: safe use sustaining the desired technical and functional properties [4]. The building should provide comfortable health and hygiene 
conditions, indoor environment, e.g., thermal, acoustic, and visual comfort, and with respect for the natural resources, i.e., raw materials, water, and energy, through the entire life cycle, subsequently limiting harmful emissions to the environment. An essential element ensuring compliance with the requirements of sustainable construction is the use of materials that meet environmental and ecological criteria. Assessment of performance of construction products under Regulation No. 305/2011 [5] should take into account environmental impacts and health aspects over the product's life cycle. Hygienic and ecological issues for ETICS systems include:

- life cycle environmental impacts and aspects, e.g., greenhouse gas emissions, acidification, eutrophication, resource consumption, water consumption, waste, and recycling,

- the presence of hazardous substances in the system and its components, together with the possibility of their emission into the environment (in the conditions of use),

- use of ETICS systems in buildings containing asbestos in external partitions,

- resistance to biological corrosion of ETICS systems (biocides).

In industrial processes, LCA is widespread and frequently used to evaluate the environmental impact of products and processes. In line with the policy of the European Commission, Environmental Product Declarations Type III (EPD) are potent tools for a better understanding of the rules of sustainable development. Type III declarations are currently a frequently used LCA format [6,7]. LCA results of EPDs consist of a wide variety of environmental impact categories and input/output indicators, which are specified by the product category rules in EN 15804 [8]. They provide brief quantified environmental information about the particular product life cycle, further allowing a comparison between products that perform the same function. Finally, they educate and create social awareness, which supports the consumer decision-making process to minimize the negative impact on the environment [9].

All this together triggered a subsequent demand from producers of building materials to assess the impacts of their activities on the environment. Nowadays, based on real data, they are investigating ways of improving the environmental performance of their products by substituting raw materials by recycled ones, both reducing energy consumption and adopting strategies on pollution control.

As a result of the European Union's activities, construction has become a leading branch of the economy that has an impact on the issues of energy saving, the use of energy from renewable sources, and the minimization of greenhouse gas emissions. However, only the Regulation (EU) No 305/2011 [5] published in 2011, introduced a new basic requirement for the sustainable use of natural resources. Yet, to date, the essential characteristics for sustainable development necessary to assess the product have not been determined. Thus, the environmental aspects of construction products are voluntary, and data from EPD are used, primarily in B2B communications and involuntary building certification systems such as LEED $[10,11]$ or BREEAM $[10,12]$. The number of EPDs in the European market is limited, mainly in the field of facade applications, as it is in the case of ETICS. This state of affairs limits opportunities for both comparison and material choice possibilities in case of building certification systems. Moreover, there is a somewhat limited number of ETICS scientific publications in the rich literature on LCA and EPD [13-15].

It is worth noting that the results of the environmental characteristics presented in this paper were obtained based on real data from five production locations in Poland. In addition, they correspond to the volume of production, enabling an annual installation of about 10 million square meters of ETICS.

\subsection{ETICS Systems}

ETICS systems are a solution for continuous thermal insulation of external walls of a building. The system is well proven in practice in decades. The first ETICS system was manufactured in Berlin in 1957. Moreover, countries like Austria and Switzerland ETCIS have been using it since the early 60s of the previous century [16]. In Poland, the ETICS system was first introduced at the begging of the 80s. Nowadays, it is one of the most popular and widely used methods of improving energy efficiency and refurbishing the facades of new and existing buildings. ETICS systems are kits built of elements 
consisting of specific manufactured or prefabricated components being applied directly to the facade. These system components are adhesives, thermal insulation material, anchors (if required), base coat, reinforcement, finishing coat/topcoat with system primer and/or paint coating, less often accessories, e.g., fabricated corner beads, edge profiles, and expansion joint profiles.

ETICS systems are simple in application. Their low weight allows installation on almost any building. EPS insulation boards put a little load on the bearing capacity; thus, in most cases, it does not have to be considered in the structural calculations, also during a building refurbishment. ETICS systems, when applied properly [17], offer a simple solution to problems related to continuity of thermal insulation on surfaces of foundations, walls, and underground elements, providing the following properties:

- reduction of the cost of heating, Depending on building size and a type of heating system savings, after its installment, can reach the level of a few thousand euros per year [18].

- improvement of building ability to heat accumulation, According to an accepted concept of thermic comfort, not only the interior air temperature and humidity but also the temperature of walls have an impact on our mood and perception of heat. The external layer not only protects a wall against the temperature outside but also blocks the heat within a partition. According to the rules of thermodynamics, the flow of heat leads from the areas of higher temperature to the areas of lower temperature. Because of that, ETICS systems ensure heat in the wintertime and pleasant coolness in the summer $[19,20]$.

- reduction of the consumption of energy and greenhouse gasses emission, Thermal insulation allows to reduce of the consumption of fuels and, especially when combined with other thermal modernizations, e.g., exchange of boilers, the use of better fuels, has a direct impact on the improvement of quality of air and liquidation of the smog phenomenon [21].

- influence operation durability, It helps to keep its operational performance and functionality after a long time. ETICS systems eliminate the possibility of water vapor condensation in the walls and prevent the growth of fungi and mold [22]. With no thermal insulation, a sudden temperature drop takes place in a wall structural material and-due to its low thermal resistance-puts it at risk of condensed moisture freezing. This action gradually destroys the building structure.

- protection against direct action of atmospheric factors, Appropriately selected system top coats-thin-coat renders and paints-form a barrier against precipitation. Owing to their parameters, the thermal insulation is protected against damp and growth of mold [21].

ETICS systems change our surroundings. Diversity of textures, hundreds of colors and possible solutions bring almost unlimited options for a facade designer. Thermal insulation systems supplant dullness and uniformity from our settlements and streets. Owing to ETICS, a designer can feel free to form outstanding arrangements, impart uniqueness to facades and combine different techniques and decorative effects [23].

\subsection{Research Question}

The authors hypothesize that the selection of raw materials, partial materials of the system, and component processes have an impact on the environmental assessment of the entire system. Their responsible range, while maintaining excellent technical properties, is the right address for sustainable construction in the planning and development of production processes.

\section{Materials and Methods}

\subsection{Goal and Scope}

The goal of this work was to compare the LCA results of the EPS based ETICS system, the most popular up to date thermal insulation material, with different renderings based on the site-specific data of the examined product referring to the production year 2012 [24] and 2017 [25]. The authors 
in their research mainly focused on determining the LCA-based environmental impacts of a selected group of ETICS systems. The authors were interested in assessing the effect of the rendering types on the result of the overall ETICS systems impact. An essential element of the study is to show changes in the environmental impact of the product over time.

\subsection{LCA Methodology Declared Unit and System Boundaries}

LCA is an internationally accepted methodology for assessing the environmental impact of construction materials, elements, and systems. The methods described in the standard ISO 14040 [26], ISO 14044 [27], and EN 15804 [8] series consist of goal and scope definitions, an inventory analysis (LCI), impact assessment (LCIA) and phases interpretation. While LCI is the phase in which inputs and results are calculated, LCIA aims to understand and evaluate the size and significance of environmental impacts for a product system throughout the product life cycle. The common functional unit for the complete ETICS system is the area of application of the insulation $\left(1 \mathrm{~m}^{2}\right)$ with a defined thickness of the insulating material. The life cycle stages of construction materials and products are already standardized at the European level [8]. LCA study can be divided into three different considered levels: cradle-to-gate (raw materials extraction and processing up to the finished product), cradle-to-grave, where transport, distribution, assembly, use, maintenance, and final disposal are taken under, and cradle-to-cradle (taking into consideration reuse, recovery, and/or recycling potential). In this study, a cradle-to-gate approach was used. The environmental impact analysis focused on the stage A1extraction of raw materials, through stage A2- the transportation to the factory, and storage of materials used to produce ETCIS system components, up to stage A3, in which energy provision and production process were included. The cradle-to-gate approach concerns the life cycle up to the ready-to-use and packed product at the factory gate.

The analysis is based on the site-specific data of the examined product, referring to the year 2012 and further 2017. The LCA relates to products manufactured in Poland. Processes with a total contribution to the final result of less than $0.5 \%$ by weight, were ignored. The values determined to calculate the LCA originate from verified producer inventory data. The impacts of the representative products for each ETICS layer were aggregated using a weighted average. The weighted average method was used according to the percentage of each product in ETICS based on the relation to the whole production quantity. The impacts of each product and factory were inventoried and calculated separately. The data for the processes come from the following databases: Ecoinvent [28], Polish Cement data, ITB-data [29], Plastic-Europe, and specific EPDs.

\subsection{ETICS System Components}

External Thermal Insulation Composite System are kits which consist of an insulation board (bonded or bonded and mechanically fixed) with reinforced undercoat and decorative finishes, as described in the National Technical Approval ITB AT-15-9090/2014 [30] and ITB AT-15-9090/2016 [31]. The system consists of a broad selection of adhesives, base coats, renders, and decorative coats of various colors (Figure 1).

It provides a variety of solutions depending on the requirements of the building design, the investors and construction workers (Table 1). EPS based ETICS systems offer a wide range of solutions for all building types. Are fully certified according to the National and European Assessment Documents. Its specification and technical parameters meet the requirements of each project, whether residential or commercial, in compliance with all applicable building regulations in Poland. Renders taken under consideration were as follows, mineral render (MR), acrylic render (AR), silicone render ( $\mathrm{SiR}$ ), and silicone-silicate render ( $\mathrm{Si}-\mathrm{SiR}$ ). At this stage, it is essential to emphasize that in most cases, producers of ETICS systems do not produce expanded polystyrene, anchors, glass fiber mesh, and other ancillary materials. Their impacts were calculated according to available datasets and data provided by the suppliers of these materials. 


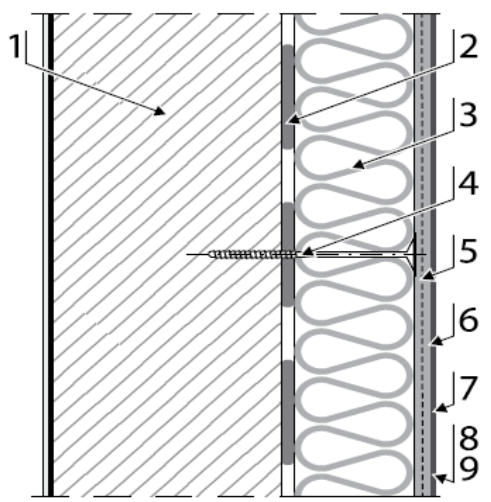

Figure 1. Layers arrangement in the ETICS system as described: (1) wall structure (substrate), (2) adhesive (basic fixing), (3) thermal Insulation (EPS), (4) anchor (if necessary, additional fixing), (5) reinforcement layer (base coat with glass fiber mesh embedded), (6) key coating (if necessary), (7) finishing coat (renders), (8) primers (optional), and (9) decorative coats (optional).

Table 1. EITCS system components as described in the National Technical Approval ITB AT-15-9090/2016.

\begin{tabular}{|c|c|c|}
\hline Category & Component Description & Quantity per $\mathrm{m}^{2}$ \\
\hline Adhesives for bonding the EPS & $\begin{array}{l}\text { Cement-based adhesives modified with } \\
\text { redispersible polymers, fibers, and mineral } \\
\text { fillers }\end{array}$ & $4.5 \mathrm{~kg}$ \\
\hline Insulation * & Prefabricated EPS board & $1.35 \mathrm{~kg}$ \\
\hline Adhesive for base coat & $\begin{array}{l}\text { Cement-based adhesives modified with } \\
\text { redispersible polymers, fibers, and mineral } \\
\text { fillers }\end{array}$ & $5.5 \mathrm{~kg}$ \\
\hline Glass fiber meshes * & $\begin{array}{l}\text { Alkaline-resistant glass mesh } \\
\text { with a nominal weight of } 150 \text { or } 165 \mathrm{~g} / \mathrm{cm}^{2}\end{array}$ & $\geq 0.15 \mathrm{~kg}$ \\
\hline Key coats & $\begin{array}{l}\text { Acrylic key coat with quartz filler } \\
\text { Mineral key coat with mineral/quartz filler }\end{array}$ & ca. $0.2 \mathrm{~kg}$ \\
\hline Finishing coats & $\begin{array}{l}\text { Mineral render } \\
\text { Acrylic render } \\
\text { Silicone render } \\
\text { Silicone-silicate render }\end{array}$ & $2.0-4.5 \mathrm{~kg}$ \\
\hline Primers (optional) & $\begin{array}{l}\text { Silicate (potassium water glass) primer } \\
\text { Silicone-silicate primer }\end{array}$ & $0.1 \mathrm{~kg}$ \\
\hline Decorative coats (optional) & $\begin{array}{l}\text { Silicate mineral-based paint } \\
\text { Acrylic-based paint } \\
\text { Silicone-based paint }\end{array}$ & $0.2 \mathrm{~kg}$ \\
\hline Ancillary materials * & Anchors, special fittings & - \\
\hline
\end{tabular}

\subsection{The Environmental Impact Categories Considered}

The assessment was expressed into seven basic impact categories, as shown in Table 2.

Moreover, the production impact on the environment, associated with the use of resources, was studied. Additional environmental impact categories that have been taken under consideration were PENRT and PERT. 
Table 2. Basic environmental impact categories used for LCA.

\begin{tabular}{|c|c|}
\hline Environmental Impact Categories & Units \\
\hline Global warming potential (GWP) & $\mathrm{kg} \mathrm{CO}_{2}$ eq. \\
\hline Ozone layer depletion potential (ODP, steady state) & $\mathrm{kg} \mathrm{CFC} 11$ eq. \\
\hline Acidification potential (AP) & $\mathrm{kg} \mathrm{SO}_{2}$ eq. \\
\hline Eutrophication potential (EP) & $\mathrm{kg}\left(\mathrm{PO}_{4}\right)^{3-}$ eq. \\
\hline Photochemical ozone creation potential (POCP) & $\mathrm{kg}$ Ethene eq. \\
\hline Abiotic depletion potential-elements (ADP) & $\mathrm{Kg} \mathrm{Sb} \mathrm{eq.}$ \\
\hline Abiotic depletion potential-fossil (ADFP) & MJ \\
\hline Total use of renewable primary energy sources (PERT) & MJ \\
\hline Total use of non-renewable primary energy sources (PENRT) & MJ \\
\hline
\end{tabular}

\subsection{Cradle to Gate Life-Cycle Inventory}

\subsubsection{Production of Dry Mixes}

The dry mixes, e.g., adhesives for bonding insulation materials, adhesive for the base coat, and mineral finishing coat, are produced according to the production process, as presented at Scheme 1. Raw materials are received in silo trucks, big-bags, or bags. Then, the materials are transported into the silo storing system through a pneumatic conveying system. Quartz sand is transported with a belt conveyor, dried in a drum dryer, and then stored in a silo system. The final product is a mixture of different components and complies with the laboratory-developed formulation. Raw materials are dosed by various systems, mostly by gravity, or a worm screw with a frequency controller, or/and a volumetric dosage through a rotary valve. The weighting of raw materials is performed within one of five weighing hoppers. Dosed components are discharged into the empty blender trough pneumatic valves. The homogenization process is defined by the mixing mode and time. These vary on the composition of the product and technological guidelines. After homogenization, the product is discharged. The last stage is packing and palletizing of the product. Regarding powders products, they are packed with the rotary filling machine in pasted multiwall paper bags, printed and produced on-site, and then put on a pallet. Finally, the pallet is wrapped in a thermoplastic pallet shrink cover.

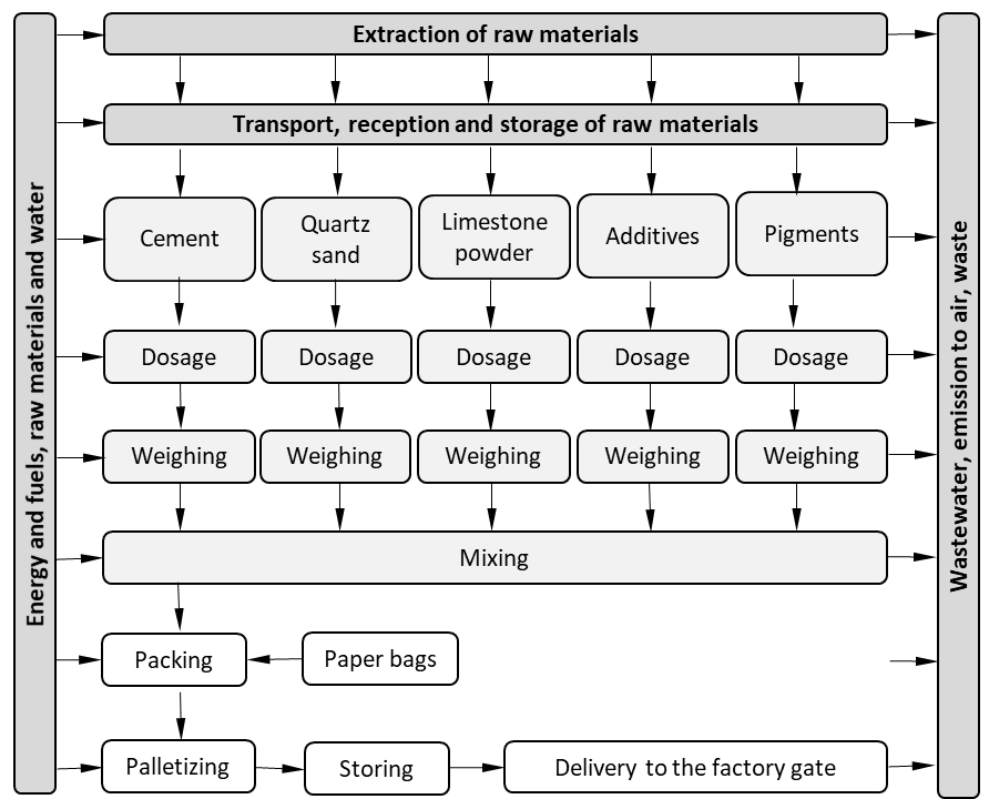

Scheme 1. The production process of dry mixes used in ETICS systems, as described in the EPD [25]. 


\subsubsection{Production of Ready-to-use Renders, Paints, and Primers}

Ready-to-use renders, e.g., key coats, and finishing coats, both acrylic, silicone, and silicone-silicate renders are produced according to the manufacturing process, as presented below in Scheme 2. Here, loose material is received in silo trucks and big bags. Liquid raw materials are received in silo trucks or intermediate bulk containers (IBC). Fillers and aggregates are transported into the silo storing system through a pneumatic conveying system or with a belt conveyor. The final product is a mixture of different components and complies with the laboratory-developed formulation. Raw materials are dosed automatically by the pneumatics system. Dosed components are discharged into the empty three roll mixer. The homogenization process is defined by the mixing mode and time. These vary in the composition of the product and technological guidelines. After homogenization, the product falls into the hopper of the mixer and it is pneumatically dosed to the $12.5 \mathrm{~m}^{3}$ holding tank with recirculation forced by an air-operated double diaphragm pump. After storying for a technologically specific amount of time, the base of the render is pneumatically dosed into the plastic buckets. Then, a ready product is put on a pallet. Finally, the pallet is wrapped in a thermoplastic pallet shrink cover. Renders that are intended to be tinted are then transported to the tinting machine system. Paints and primers are produced in the same technological manner as ready-to-use renders but without any additional use of coarse aggregates.

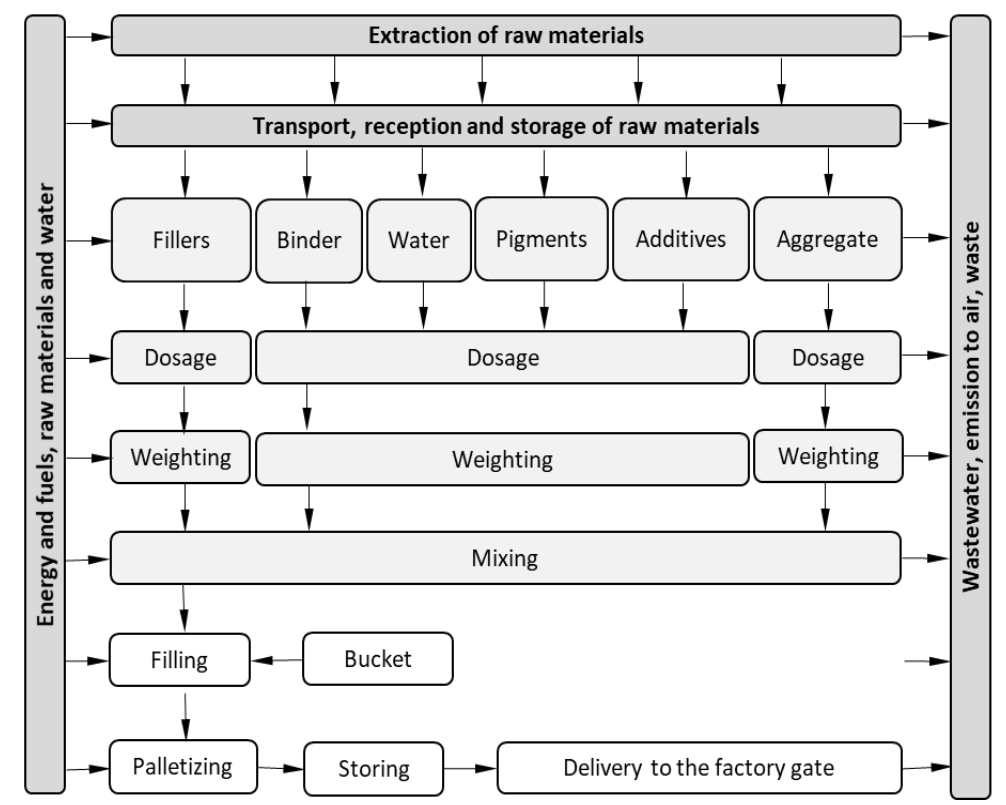

Scheme 2. The production process of ready-to-use renders used in ETICS systems, as described in the EPD [25].

\section{Results}

\subsection{Environmental Characteristics of ETICS System with Different Rendering Types}

The ETICS system that was chosen for this experiment is described by the National Technical Approval document no. ITB-15-9090/2016 and was specially designed for the use with EPS, as an insulation material. Due to the complexity of the ETICS systems, Life Cycle Analysis results regard to four different rendering systems, including mineral render (MR), acrylic render (AR), silicone render, and silicone-silicate render (Si-SiR). All the calculations were performed, taking into consideration the following thicknesses of the thermal insulation boards: 10, 15, and $20 \mathrm{~cm}$, to show, how the impact of the ETICS system on the environment changes with the change of EPS insulation thickness.

Data obtained from Life Cycle Assessment show that regarding the type of render, the mineral render shows the lowest value of environmental impacts in eight out of nine evaluated indicators 
(Table 3). Its global warming potential (GWP) of $0.87 \times 10^{1}$ was almost $10 \%$ lower than for silicone render and up to 15 and $20 \%$ lower than for acrylic and silicone-silicate render, respectively. The most significant difference among all investigated environmental impacts was observed for eutrophication potential, were mineral renders, had almost $30 \%$ lower impact on the environment than silicone-silicate renders, the worst render in this category. In abiotic depletion potential-fossil, mineral renders had more than a $45 \%$ lower result than silicone-silicate renders (Si-SiR). The worst environmental characteristic among all the investigated rendering systems was observed for acrylic render in the following categories: ODP and POCP, ADP, and PENRT. Silicone-silicate render exhibits the highest value of the following indicators: GWP, AP, EP, and PERT.

Table 3. The environmental characteristic for $1 \mathrm{~m}^{2}$ of ETICS with and the $10 \mathrm{~cm}$ thickness of expanded polystyrene. Data from the EPD, according to the production of the ETICS system in the year 2017 [25].

\begin{tabular}{|c|c|c|c|c|c|c|c|c|c|}
\hline & GWP & ODP & AP & EP & POCP & ADP & ADPF & PERT & PENRT \\
\hline MR & $0.87 \times 10^{1}$ & $5.01 \times 10^{-5}$ & $2.57 \times 10^{-2}$ & $4.62 \times 10^{-3}$ & $2.41 \times 10^{-3}$ & $1.55 \times 10^{2}$ & $9.90 \times 10^{-3}$ & $0.87 \times 10^{1}$ & $1.63 \times 10^{2}$ \\
\hline AR & $1.00 \times 10^{1}$ & $5.16 \times 10^{-5}$ & $3.16 \times 10^{-2}$ & $6.28 \times 10^{-3}$ & $3.09 \times 10^{-3}$ & $1.47 \times 10^{2}$ & $1.85 \times 10^{2}$ & $0.86 \times 10^{1}$ & $2.02 \times 10^{2}$ \\
\hline SiR & $0.94 \times 10^{1}$ & $5.01 \times 10^{-5}$ & $3.04 \times 10^{-2}$ & $5.18 \times 10^{-3}$ & $2.71 \times 10^{-3}$ & $1.75 \times 10^{2}$ & $1.47 \times 10^{2}$ & $1.12 \times 10^{1}$ & $1.95 \times 10^{2}$ \\
\hline Si-SiR & $1.05 \times 10^{1}$ & $5.08 \times 10^{-5}$ & $3.44 \times 10^{-2}$ & $6.81 \times 10^{-3}$ & $2.88 \times 10^{-3}$ & $1.75 \times 10^{2}$ & $2.16 \times 10^{2}$ & $0.81 \times 10^{1}$ & $1.84 \times 10^{2}$ \\
\hline
\end{tabular}

The difference between considered environmental impact indicators of the calculated system was observed even more significant when comparing the thicknesses of thermal insulation material. Further addition of each $5 \mathrm{~cm}$ of thermal insulation material to the system changes the environmental impact categories value by an average of $40 \%$ in the following indicators: ADPF and PENRT, $25 \%$ in GWP and POCP, $20 \%$ for AP and 10\% to EP and PERT (data not shown). No concomitant differences in ODP and ADP indicators were observed.

Taking into account the extraction and transportation of the raw material to the factory (A1 and A2 stage), the EPS footprint is responsible for almost half of the global warming potential (GWP) impact of the investigated ETICS systems (Figure 2).

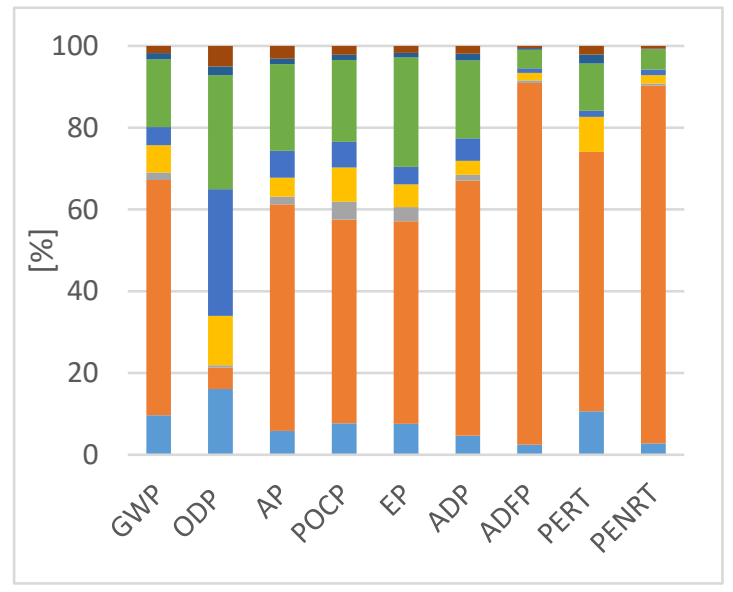

(a)

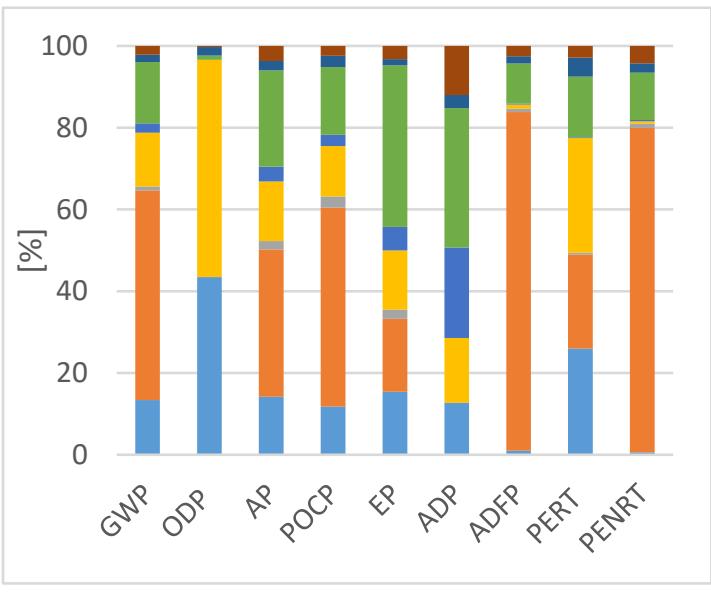

(b)

Figure 2. Environmental impact of complete ETICS system produced according to the National Technical Approval ITB-15-9090 in the year (a) 2012, and (b) 2017. The thickness of the EPS thermal insulation board: $10 \mathrm{~cm}$. The data represent the sum of environmental impact from A1 to A2 stage of ETICS life cycle assessment. The data represent the mean value obtained from the analysis of different renderings, e.g., mineral render, acrylic render, silicone render, and silicone-silicate renders. Legend: $(\square)$ adhesive for bonding insulation, $(\square)$ insulation material, $(\square)$ glass fiber mesh, $(\square)$ adhesives for base coats, ( $\square$ ) key coats, ( $\square$ ) finishing coats, $(\square)$ primers, and ( $\square$ ) decorative coats. 
It contributes to $51.3 \%$ of GWP for the $10 \mathrm{~cm}$ thick insulation, and trough ca. $61 \%$ for the $15 \mathrm{~cm}$ insulation reaching more than $68 \%$ for $20 \mathrm{~cm}$ thick insulation, having a substantial impact on a system as whole (when taking into account the fact that EPS as an ETICS component contributes only in the raw materials extraction stage). The shear of EPS production and transport changed significantly over the years from $55 \%$ to $36 \%$ in the AP impact category, from $50 \%$ to $17 \%$ in the EP impact category, and from $63 \%$ to $20 \%$ in the PERT impact category. In the category of abiotic depletion potential, it dropped off to nothing. Where no significant change in other categories was observed. This change was followed by the growth of the shear of two system components, adhesives for bonding insulation material and base coat, and finishing coats.

Considering production at the factory site, the A3 stage of the assessment, which contributes completely to the production of ETICS system components, no significant change was observed (Figure 3). In the year 2012, the average share for adhesives for bonding of insulation material was at the level of $32 \%$, for adhesives for the base coat of $31 \%$ and $28 \%$ for finishing coats. In the year 2017, calculate ozone layer depletion potential dropped to zero. Greater influence of primer and decorative coats on eutrophication potential was also observed. The change was from around $4 \%$ to $10 \%$ and $24 \%$ for primers, and decorative coats, respectively. Nevertheless, the changes observed in the stage A3 are minor concerning changes in A1 and A2 stages.

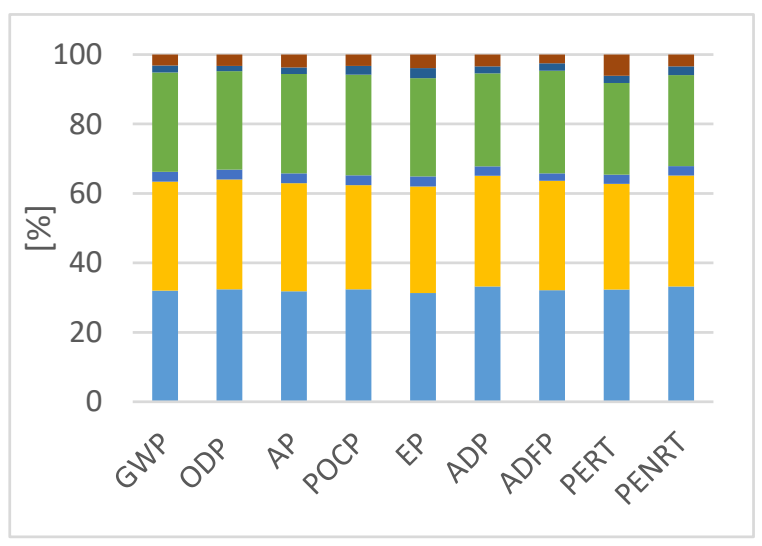

(a)

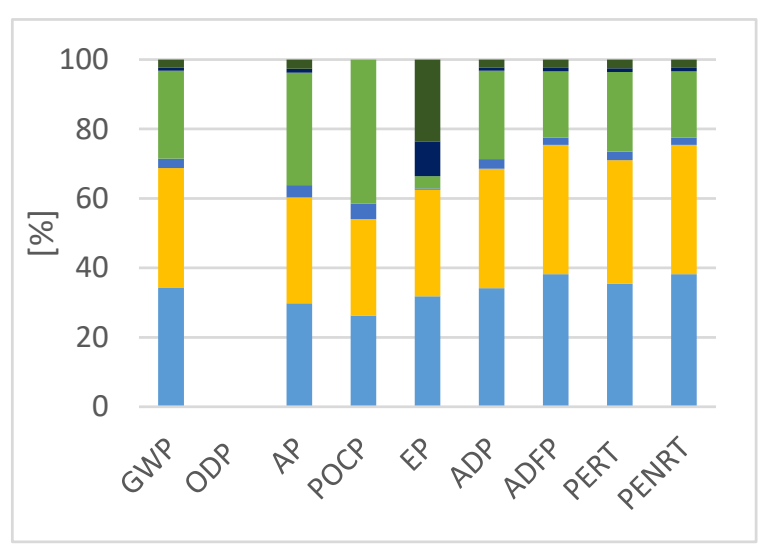

(b)

Figure 3. Environmental impact of complete ETICS system with $10 \mathrm{~cm}$ thick EPS thermal insulation produced in the year (a) 2012, and (b) 2017. The data represent the sum of environmental impact from the A3 stage of the ETIC life cycle. Finishing coats represent mean value obtained from the analysis of different renderings, e.g., mineral renders, acrylic render, silicone render and silicone-silicate render. Legend: $(\square)$ adhesive for bonding insulation, $(\square)$ glass fiber mesh, ( $\square$ ) adhesives for base coats, ( $\square$ ) key coats, ( $\square$ ) finishing coats, ( $\square)$ primers, and ( $\square)$ decorative coats.

The data presented in Figure 4 show the relative contribution of each sub-stage (A1-A3) to each impact category of ETICS systems produced in the year 2012 and 2017 is shown in Figure $4 \mathrm{a}, \mathrm{b}$, respectively.

It reflects the weight of the raw materials within the production process of these products in all environmental categories. In the year 2012, extraction of raw materials stage had a contribution of $82 \%$, or more, to all environmental impact categories, except ODP and EP, where the contribution of the A2 stage was, respectively, more than $40 \%$ and $14 \%$. The transportation processes were modeled based on the complete producer information (i.e., type of transport, average distances, type of trucks, and load factors, when applicable). Only for ozone layer depletion potential (ODP) and PERT, the impact of the on-site production stage was significant. It amounted to almost $15 \%$ and $16 \%$, respectively. In the year 2017, the extraction of the raw materials stage had a mean contribution of $96.7 \%$ to all described 
categories. As shown in Figure $4 \mathrm{~b}$, the contribution of the A3 module to the overall environmental impacts of ETICS was around an average of $2 \%$.

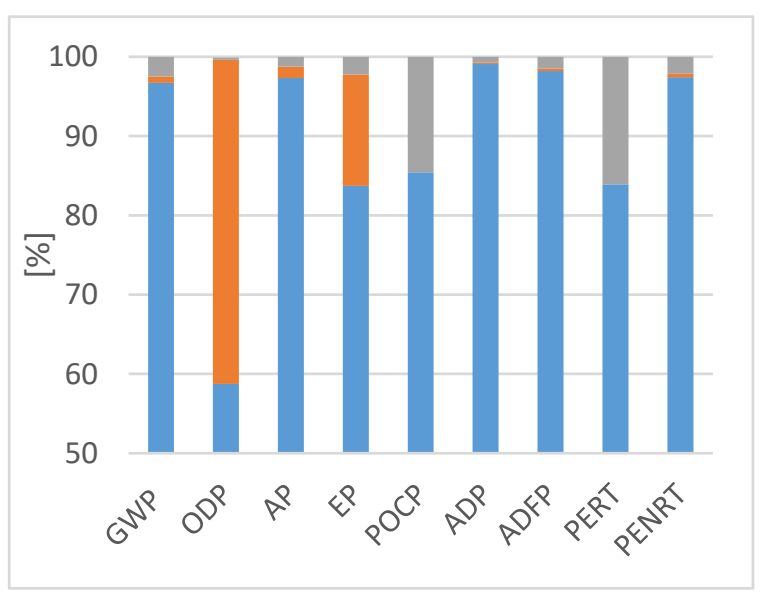

(a)

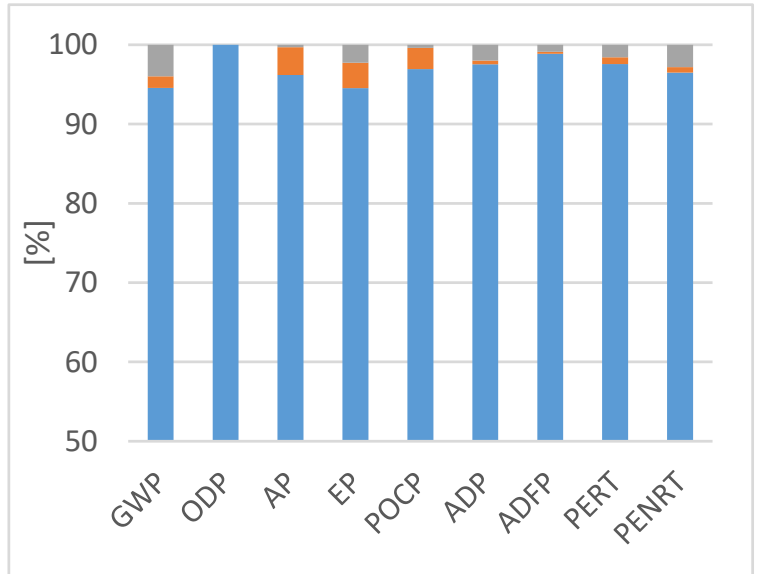

(b)

Figure 4. Environmental impact of ETICS (10 cm EPS) with mineral render with an indication of the main environmental impact categories at different A1-A3 LCA stages (a) data from 2012 and (b) data from 2017. Legend: ( $\square$ ) A1 stage, ( $\square$ ) A2 stage, and ( $\square$ ) A3 production stage.

\subsection{Detailed Comparison of Environmental Impacts of ETICS with Different Rendering Systems over the Years}

Table 4 shows the percentage change of parameter GWP calculated for the ETICS system produced between the years 2012 and 2017. During the last five-year period, the value of GWP decreased by more than $20 \%$ for mineral, acrylic, and silicone render. Regarding the type of render used as a final layer of the ETICS system, the thickness of the EPS board used as thermal insulation also influenced the change of the impact factor. As the influence of the thickness of the material had a minor influence on the change of environmental impacts for mineral, acrylic, and silicone render, that for silicone-silicate render the influence of the thickness was substantial. Here, the authors observed a change from $12 \%$ up to $18 \%$ regarding the thickness of the insulation material. A similar tendency was observed for the decrease of acidification potential (Table 4 ) of the described ETICS system with an even greater difference between thicknesses of EPS, showing its influence on the overall positive effect. The change of acidification potential for ETICS produced between the years 2012 and 2017 were greater than $25 \%$ for mineral and silicone render, and greater than 30\% for an acrylic finishing layer. The minor change was observed for silicone-silicate render, nevertheless, the decrease of AP was greater than $14 \%$ for the ETICS system with $10 \mathrm{~cm}$ thick thermal insulation material, and further $22 \%$ and $27 \%$ for 15 and $20 \mathrm{~cm}$ thick EPS board, respectively. Interestingly, the eutrophication potential increased over for 5 years for mineral, acrylic, and silicone-silicate renders (Table 4). Here, the strong influence of the thickness of the insulation material was observed. The data show that for the ETICS system with mineral render, the value of the impact factor investigated reversed for the system with a 20 -cm-thick layer of insulation material. 
Table 4. The comparison of environmental impact categories for ETICS systems with different renderings produced in 2012 and 2017. MR - mineral render, AR - acrylic render, Si - silicone render, Si-SiR silicone-silicate render.

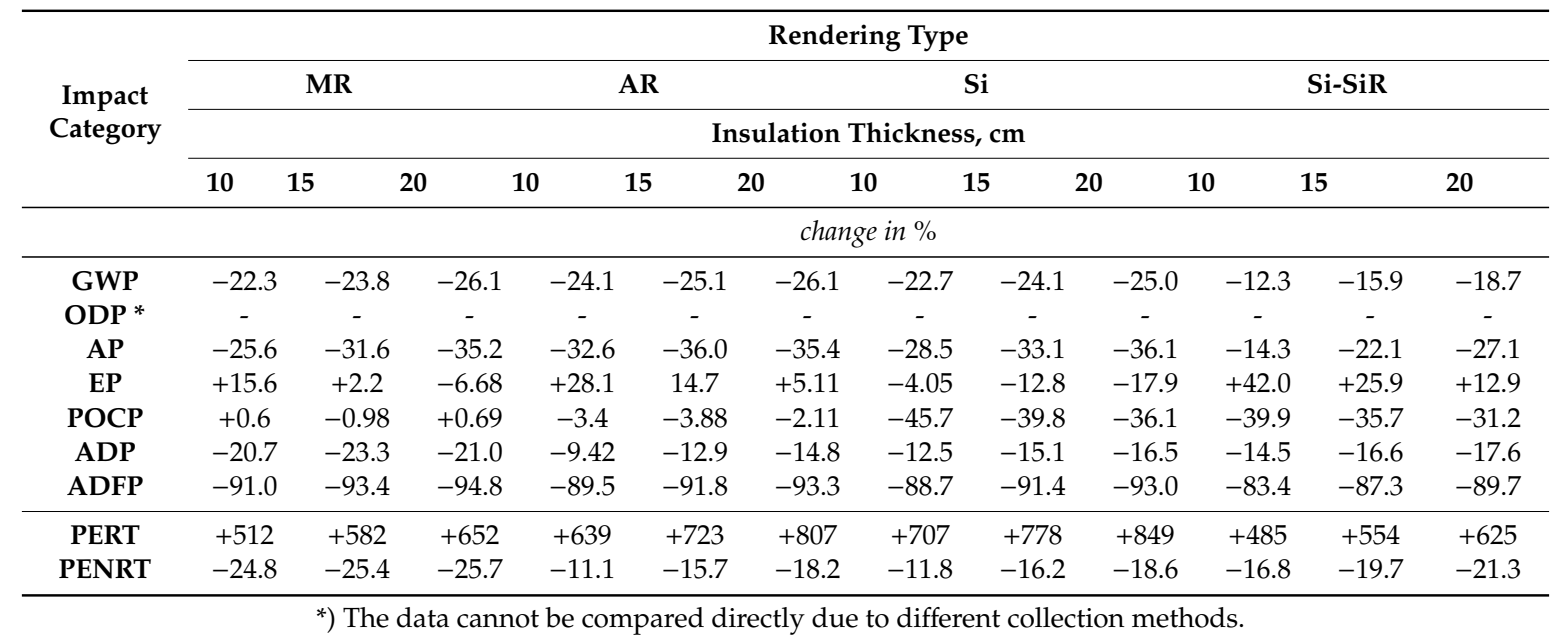

\section{Discussion}

A lowered environmental impact in the category of eutrophication potential was observed only for the ETICS system with a silicone rendering system. The value of photochemical ozone creation potential (POCP) factor for the ETICS system with mineral and acrylic renders did not change significantly over the investigated period for mineral and acrylic renders (Table 4). On the other hand, the value of POCP for silicone and silicone-silicate renders changed by more than $40 \%$ with the negative influence of thermal insulation material thickness, which lowered the positive change average by four percentage points per $5 \mathrm{~cm}$ of EPS board applied in the system. Here, a decrease of the abiotic depletion potential factor value for both ADP and ADFP, was observed (Table 4). A significant change over the investigated years was completely diminished (more than a $90 \%$ decrease in the environmental factor value). The changes were almost independent of the thickness of the insulation material, according to the additional environmental impact categories that were taken into consideration (Table 4). The most amazing change was observed for the PERT across the last 5 years of production. In total, the use of renewable energy changed from $500 \%$ to $800 \%$, with a concomitant decrease of non-renewable primary energy sources from $10 \%$ to $25 \%$. This demonstrates significant changes in the ways of producing energy used in production and the departure from the use of fossil fuels.

In addition to the presented results for a representative group of products, the authors of ITB, as part of their research, determined the average values of environmental impacts concerning $\mathrm{kg}$ of the product for almost all ETICS component products on the domestic market (Table 5). The results for these products lead to the conclusion that the less the product is modified by the substances that change the properties of plasters and adhesives, the lower the impact.

Based on the results provided in this article, the authors showed that considering the A1-A3 product stage of the ETICS system, the most significant influence on total environmental impact in all the investigated categories was the extraction of raw materials followed by the production of intermediates used to produce each ETICS system component. In more detail, the results show that in most of the categories in 2012, the biggest influence on their value was the insulation material itself. According to the LCA results interpretation for EPS production, all impact categories except POCP are dominated by the influence of the EPS board production, especially abiotic depletion and PENRT. EPS is produced out of polystyrene beads. These are produced from refined petroleum products. 
Table 5. Approximate values (average) of environmental impacts of products entering the ETICS system concerning $1 \mathrm{~kg}$ of product (2010-2016, ITB)-A1-A3 modules. MR-mineral render, AR-acrylic render, $\mathrm{Si}$-silicone render, $\mathrm{SiR}$ - silicate render, $\mathrm{Si}-\mathrm{SiR}$ — silicone-silicate render.

\begin{tabular}{llllllll}
\hline Impact [unit] & MR & AR & Si & SiR & Si-SiR & Paint & Binder \\
\hline GWP $[\mathrm{kg} \mathrm{CO}$ C $]$ & 0.40 & 1.00 & 0.70 & 0.60 & 0.70 & 1.50 & 0.4 \\
ODP $[\mathrm{kg} \mathrm{CFC} \mathrm{11]}$ & $6.5 \times 10^{-8}$ & $1.5 \times 10^{-7}$ & $1.5 \times 10^{-7}$ & $1.4 \times 10^{-7}$ & $1.4 \times 10^{-7}$ & $2.8 \times 10^{-7}$ & $6.2 \times 10^{-8}$ \\
\hline AP $\left[\mathrm{kg} \mathrm{SO}_{2}\right]$ & 0.001 & 0.005 & 0.004 & 0.0020 & 0.0030 & 0.006 & 0.0005 \\
\hline EP $\left[\mathrm{kg}\left(\mathrm{PO}_{4}\right)^{3-}\right]$ & 0.0001 & 0.0004 & 0.0006 & 0.0002 & 0.0004 & 0.001 & 0.0001 \\
\hline POCP $[\mathrm{kg} \mathrm{Ethene]}$ & 0.0001 & 0.0003 & 0.0002 & 0.0001 & 0.0002 & 0.001 & 0.0001 \\
\hline ADP $[\mathrm{kg} \mathrm{Sb]}$ & 0.003 & 0.020 & 0.010 & 0.008 & 0.010 & 0.020 & 0.001 \\
ADFP $[\mathrm{MJ}]$ & 2.5 & 5.0 & 3.8 & 2.8 & 3.5 & 7.5 & 1.5 \\
\hline
\end{tabular}

As a result of the depletion of fossil fuels during the production, a high impact in the abiotic depletion potential-fossil (ADPF) was observed and consists of almost $80 \%$ of the total value of the impact category. Moreover, the foaming process of polystyrene beads contributes significantly to the environmental impact investigated. The emission of gasses during that process contributes to the increase in the POCP value. Changes in environmental impact categories for the ETICS system are well correlated with the changes in environmental impact categories of expanded polystyrene, especially in categories where the share of EPS environmental impact is high (Table 6).

Table 6. Comparison of LCA results for expanded polystyrene. The data were provided by the Association for European Manufacturers of Expanded Polystyrene members across Europe. Comparison based on data obtained from production between 2009 and 2015 [32,33].

\begin{tabular}{lrrr}
\hline & The Year 2009 & The Year 2015 & Change [\%] \\
\hline GWP & $7.97 \times 10^{1}$ & $7.86 \times 10^{1}$ & -1.5 \\
ODP & $2.81 \times 10^{-6}$ & $4.92 \times 10^{-9}$ & -99.8 \\
AP & $1.93 \times 10^{-1}$ & $1.89 \times 10^{-1}$ & -2.3 \\
EP & $1.87 \times 10^{-2}$ & $1.84 \times 10^{-2}$ & -1.8 \\
POCP & $4.20 \times 10^{-1}$ & $3.69 \times 10^{-1}$ & -12.2 \\
ADP & $1.5 \times 10^{-5}$ & $3.80 \times 10^{-5}$ & 152.9 \\
ADFP & $2.31 \times 10^{3}$ & $2.20 \times 10^{3}$ & -4.9 \\
PERT & $1.41 \times 10^{1}$ & $4.89 \times 10^{1}$ & 241.6 \\
PENRT & $2.39 \times 10^{3}$ & $2.25 \times 10^{3}$ & -5.9 \\
\hline
\end{tabular}

According to the data provided from the Environmental Product Declaration for EPS and by EUMEPS membership from all parts of Europe, a substantial change can be seen in categories like ODP, POCP, ADP, ADFP, PERT, and PENRT.

\section{Conclusions}

To date, Environmental Product Declarations have mainly been used in the construction industry as a tool for communications. They were also required for green building certification, e.g., calculation of the building life cycle assessment. Nevertheless, what is most important is that the information obtained from EPDs, and further evaluated LCA be used for a company's internal product benchmark and ecological optimization of a whole production value chain. Here, in this article, we showed that the main influences of ETICS systems on the environment were neither the production process of system components, nor the internal transport at the manufacturing site, but the choice of raw materials used to produce system components, and suitable system components themselves. However, considering internal transport and the production process, there still exists the possibility to optimize the production process, mainly by diversification of energy sources, a higher use for renewable energy sources over 
non-renewable, better production waste management or recycling during production, and finally, more strict quality control, but those are minor according to the obtained LCA calculations data. In order to reduce the environmental impact of the ETICS systems and fulfill all seven basic requirements of Regulation (EU) No 305/2011, which are related to the safety of building and surrounding environment, we should optimize the parameters such as reaction to fire, heat conduction, sound insulation and water resistance, chemical resistance, and biological resistance, but with the use of new ecologically optimized materials. Selecting the right raw materials, we should pay attention not only to the technical and economic aspects but also on the environmental aspect. The use of innovative raw materials or same materials produce with the use of innovative technology, optimized transport, and location of manufacturing process, can give further development in the performance of ETICS systems simultaneously lowering the impact on the natural environment, also in the aspect of durability and save of the energy across whole life of ETICS systems.

Author Contributions: Conceptualization, B.M., and J.M.; formal analysis, M.M., J.T., and M.P.; investigation, M.M., and J.T.; methodology, J.T., S.C., and M.P.; project administration, J.M.; resources, M.M., and J.T.; supervision, R.G., and J.M., validation, M.P., and J.T.; visualization, B.M., writing - original draft preparation, B.M., writing - review \& editing, B.M., J.T., M.P., and J.M. All authors have read and agreed to the published version of the manuscript.

Funding: This research was partially supported by the Smart Growth Operational Programme 2014-2020 (Project number POIR.02.01.00-00-0350/16).

Conflicts of Interest: The authors declare no conflict of interest.

\section{References}

1. Thant, U. Problems of the Human Environment; Report of the Secretary-General; United Nations Economic and Social Council: New York, NY, USA, 1969.

2. Meadows, D.H.; Meadows, D.L.; Randers, J.; Behrens, W.W. The Limits to Growth: A Report to The Club of Rome. Universe 1972, 1-9.

3. Pacheco-Torgal, F.; Cabeza, L.F.; Labrincha, J.; de Magalhaes, A. Eco-Efficient Construction and Building Materials: Life Cycle Assessment (LCA), Eco-Labeling and Case Studies; Woodhead Publishig: New York, NY, USA, 2014; ISBN 9780857097675.

4. Czarnecki, L.; Van Gemert, D. Innovation in construction materials engineering versus sustainable development. Bull. Polish Acad. Sci. Tech. Sci. 2017, 65, 765-771. [CrossRef]

5. Regulation (EU) No 305/2011 Regulation (EU) No 305/2011 of the European Parliament and of the Council. Available online: https://eur-lex.europa.eu/legal-content/EN/TXT/?uri=uriserv:OJ.L_.2011.088.01.0005.01. ENG\&toc=OJ:L:2011:088:TOC (accessed on 21 November 2019).

6. Bovea, M.D.; Ibáñez-Forés, V.; Agustí-Juan, I. Environmental product declaration (EPD) labeling of construction and building materials. In Eco-Efficient Construction and Building Materials: Life Cycle Assessment (LCA), Eco-Labelling and Case Studies; Woodhead Publishing: New York, NY, USA, 2014; ISBN 9780857097675.

7. Brinkmann, T.; Metzger, L. Ecological assessment based on environmental product declarations. In Sustainable Production, Life Cycle Engineering and Management; Springer: Cham, Switzerland, 2019; pp. 21-31.

8. CEN. EN 15804 Sustainability of Construction Works-Environmental Product Declarations-Core Rules for the Product Category of Construction Products; European Committee for Standardization: Brussels, Belgium, 2012.

9. Petrovic, B.; Myhren, J.A.; Zhang, X.; Wallhagen, M.; Eriksson, O. Life cycle assessment of building materials for a single-family house in Sweden. Energy Procedia. 2019, 158, 3547-3552. [CrossRef]

10. Bitsiou, E.; Giarma, C. Parameters related to building components' life-cycle analysis in methods for buildings' environmental performance assessment. IOP Conf. Ser. Earth Environ. Sci. 2020, 410, 012066. [CrossRef]

11. Gelowitz, M.D.C.; McArthur, J.J. Investigating the Effect of Environmental Product Declaration Adoption in LEEDßon the Construction Industry: A Case Study. Procedia Eng. 2016, 145, 58-65. [CrossRef]

12. Andersen, S.C.; Larsen, H.F.; Raffnsøe, L.; Melvang, C. Environmental Product Declarations (EPDs) as a competitive parameter within sustainable buildings and building materials. IOP Conf. Ser. Earth Environ. Sci. 2019, 323, 012145. [CrossRef] 
13. Sierra-Pérez, J.; Boschmonart-Rives, J.; Gabarrell, X. Environmental assessment of façade-building systems and thermal insulation materials for different climatic conditions. J. Clean. Prod. 2016, 113, 102-113. [CrossRef]

14. Dylewski, R.; Adamczyk, J. Study on ecological cost-effectiveness for the thermal insulation of building external vertical walls in Poland. J. Clean. Prod. 2016, 133, 467-478. [CrossRef]

15. Silvestre, J.D.; Castelo, A.M.P.; Silva, J.J.B.C.; Brito, J.M.C.L.; Pinheiro, M.D. Retrofitting a building's envelope: Sustainability performance of ETICS with ICB or EPS. Appl. Sci. 2019, 9, 1285. [CrossRef]

16. Künzel, H. Außenseitige Wärmedämmung und Witterungsschutz (External Thermal Insulation and Weathering Protection). Gesund. Ing. 1975, 96, 132-139.

17. Sulakatko, V. Modelling the technical-economic relevance of the ETICS construction process. Buildings 2018, 8, 155. [CrossRef]

18. Künzel, H.; Künzel, H.M.; Sedlbauer, K. Long-Term Performance Of External Thermal Insulation Systems (ETICS). Architectura 2006, 5, 11-24.

19. Kisilewicz, T. On the role of external walls in the reduction of energy demand and the mitigation of human thermal discomfort. Sustainability 2019, 11, 1061. [CrossRef]

20. Firlag, S.; Piasecki, M. NZEB renovation definition in a heating-dominated climate: A case study of Poland. Appl. Sci. 2018, 8, 1605. [CrossRef]

21. Kienzlen, V. The Significance of Thermal Insulation Arguments Aimed at Overcoming Misunderstandings, 3rd ed.; KEA Climate Protection and Energy Agency of Baden-Württemberg GmbH: Karlsruhe, Germany, 2014.

22. Barreira, E.; De Freitas, V.P. External thermal insulation composite systems: Critical parameters for surface hygrothermal behavior. Adv. Mater. Sci. Eng. 2014, 2014, 650752. [CrossRef]

23. Garecki, M. External Wall Insulation Systems. Guidebook Part 2: Atlas Thermal Insulation Systems, 1st ed.; Atlas sp. z o.o.: Lodz, Poland, 2019.

24. Building Research Insitute. Environmental Product Declaration Atlas ETICS External Thermal Insulation Composite System with Expanded Polystyrene Boards (EPS); Building Research Insitute: Warsaw, Poland, 2014.

25. Building Research Insitute. Environmental Product Declaration Atlas ETICS External Thermal Insulation Composite System with Expanded Polystyrene Boards (EPS); Building Research Insitute: Warsaw, Poland, 2019.

26. ISO. Environmental Management-Life Cycle Assessment_Principles and Framework; ISO 14040:2006; International Organization for Standardization: Geneva, Switzerland, 2006.

27. ISO. Environmental Management_Life Cycle Assessment-Requirements and Guidelines; ISO 14044:2006; International Organization for Standardization: Geneva, Switzerland, 2006.

28. Wernet, G.; Bauer, C.; Steubing, B.; Reinhard, J.; Moreno-Ruiz, E.; Weidema, B. The ecoinvent database version 3 (part I): overview and methodology. Int. J. Life Cycle Assess. 2016, 21, 1218-1230. [CrossRef]

29. Piasecki, M. Chosen Assessment Criteria for Building Sustainable Development Compliance; Building Research Institute: Warsaw, Poland, 2008.

30. Building Research Insitute. National Technical Approval ITB-AT-9090/2014 Zestaw Wyrobów do Wykonywania Ociepleń Ścian Zewnętrznych Budynków Systemem Atlas ETICS; Building Research Insitute: Warsaw, Poland, 2014.

31. Building Research Insitute. National Technical Approval ITB-AT-9090/2016 Zestaw Wyrobów do Wykonywania Ociepleń Ścian Zewnętrznych Budynków Systemem Atlas ETICS; Building Research Insitute: Warsaw, Poland, 2016.

32. EUMEPS. Environmental Product Declaration Number EPD-EPS-20130077-CBG1-EN: Expanded Polystyrene (EPS) Foam Insulation; EUMEPS: Berlin, Germany, 2011.

33. EUMEPS. Environmental Product Declaration Number EPD-EUM-20160270-IBG1-EN: Expanded Polystyrene (EPS) Foam Insulation; EUMEPS: Berlin, Germany, 2017.

(C) 2020 by the authors. Licensee MDPI, Basel, Switzerland. This article is an open access article distributed under the terms and conditions of the Creative Commons Attribution (CC BY) license (http://creativecommons.org/licenses/by/4.0/). 